\title{
UTILIDAD DE LAS CITOCINAS COMO MARCADORES DE AGRESIÓN QUIRÚRGICA, EN EL SÍNDROME DE ISQUEMIA-REPERFUSIÓN Y EN LA FUNCIÓN POSTRASPLANTE RENAL, EN UN MODELO EXPERIMENTAL DE AUTOTRAPLANTE RENAL LAPAROSCÓPICO VERSUS ABIERTO
}

Ana Isabel Linares Quevedo', Francisco Javier Burgos Revilla², Juan José Villafruela Sanz, Javier Zamora Romero4, Julio Pascual Santos³, Roberto Marcén Letosa3, Begoña Cuevas Sánchez, Javier Sáenz Medina? y Carlos Correa Gorospe 4 .

Servicio de Urología 1. Hospital de Fuenlabrada. Fuenlabrada. Madrid. Servicios de Urología², Nefrología y Unidad de Apoyo a la Investigación 4 . Hospital Ramón y Cajal. Universidad de Alcalá. Madrid. España.

\begin{abstract}
Resumen.- OBJETIVOS: Analizar comparativamente los niveles de citocinas producidos durante la nefrectomía laparoscópica y abierta de donante vivo para trasplante, como marcadores de agresión tisular dependiendo del tipo de técnica quirúrgica empleada y su influencia sobre el síndrome de isquemia-reperfusión y la función del injerto.
\end{abstract}

MÉTODOS: Se realizó sobre un modelo de autotrasplante renal (TR) en 30 cerdos divididos en dos grupos de 15 animales cada uno: a un grupo se le practicó nefrectomía abierta y al segundo grupo nefrectomía laparoscópica.
Ana Isabel Linares Quevedo Seseña, 46. Portal C, 3 A. 28024 Madrid. (España). analinaresquevedo@hotmail.com Trabajo recibido: 28 de agosto 2007.
RESULTADOS: Los niveles de IL-2, IL-6, IL-10 y factor de necrosis tumoral (TNF) fueron significativamente menores durante la nefrectomía laparoscópica: $6,8 \pm 0,6$ vs $13,9 \pm 1,1 \mathrm{pg} / \mathrm{ml}$ para $1 \mathrm{l}-2,46,2 \pm 2,3$ vs $84,4 \pm 2,5$ $\mathrm{pg} / \mathrm{ml}$ para $\mathrm{ll}-6,26,1 \pm 2,4$ vs $92,8 \pm 12,6 \mathrm{pg} / \mathrm{ml}$ para $1 \mathrm{~L}-10$, y $17,6 \pm 2,1$ vs $38,5 \pm 4,8 \mathrm{pg} / \mathrm{ml}$ para TNF. No existió asociación entre el flujo sanguíneo renal $(F S R)$ y los niveles de citocinas durante la fase de extracción: IL-2 ( $p=0,498)$, IL-6 ( $p=0,117)$, IL- 10 ( $p=0,081)$ y TNF ( $p=0,644)$. Sin embargo, existió correlación entre los niveles de IL-10 y el descenso de FSR al final del autoTR: ( $\left.R^{2} \quad 0,48 ; p=0,02\right)$. La función inicial del injerto se correlacionó con el FSR y los niveles de IL-2 levels durante la nefrectomía $\left(R=0,831, R^{2}=0,691, p=\right.$ $0,025)$, y el FSR de reperfusión $\left(R=0,784, R^{2}=0,614\right.$, $p<0,00011$. La función tardía del injerto se correlacionó con el FSR postTR $\left(R=0,537, R^{2}=0,289, p=0,002\right)$ y el nivel de IL-2 durante la extracción $\left(R=0,685, R^{2}=\right.$ $0,469, p=0,0151$.

CONCLUSIONES: Los niveles de citocinas fueron significativamente superiores en los animales sometidos a nefrectomía abierta que a nefrectomía laparoscópica. Los valores altos de FSR durante la extracción y el TR, y los niveles elevados de IL-10 durante el TR, mejoraron la función del injerto en el postTR inmediato. Valores de FSR bajos y niveles elevados de IL-2 durante la extracción afectaron negativamente a la función del injerto durante la primera semana postrasplante.

Palabras clave: Citocinas. Trasplante. Modelo porcino. 
Summary.- OBJECTIVES: To analyze the modifications induced by laparoscopic and open nephrectomies in living donor transplantation on cytokines, to evaluate operative trauma of different surgical techniques and the influence on ischemia/reperfusion syndrome and renal function.

METHODS: Thirty pigs underwent left nephrectomy, 15 by laparoscopy and 15 by open approach in an experimental autotransplantation model.

RESULTS: Serum level of IL-2, IL-6, IL-10 and tumor necrosis factor (TNF) were lower during laparoscopic than open nephrectomy: $6,8 \pm 0,6$ vs $13,9 \pm 1,1 \mathrm{pg} / \mathrm{ml}$ for $\mathrm{ll}-2,46,2 \pm 2,3$ vs $84,4 \pm 2,5 \mathrm{pg} / \mathrm{ml}$ for $\mathrm{ll}-6,26,1 \pm 2,4$ vs $92,8 \pm 12,6 \mathrm{pg} / \mathrm{ml}$ for $1 \mathrm{~L}-10$, and $17,6 \pm 2,1 \mathrm{vs}$ $38,5 \pm 4,8 \mathrm{pg} / \mathrm{ml}$ for TNF. There was no association between renal blood flow (RBF) and cytokines levels during nephrectomy: $I L-2(p=0,498), \| L-6(p=0,117)$, IL-10 ( $p=0,081)$ y TNF $(p=0,644)$. However, there was correlation between $1 \mathrm{~L}-10$ and the decrease of RBF after transplantation: $\left(R^{2} 0,48 ; p=0,02\right)$. Initial serum creatinine levels were correlated with RBF and IL-2 levels during nephrectomy $\left(R=0,831, R^{2}=0,691, p=\right.$ $0,025)$, and postransplantation $R B F\left(R=0,784, R^{2}=\right.$ $0,614, p<0,00011$. Seventh day creatinine levels were correlated with postransplantation $\operatorname{RBF}\left(R=0,537, R^{2}=\right.$ $0,289, p=0,002$ ) and IL-2 levels during nephrectomy $\left(R=0,685, R^{2}=0,469, p=0,015\right)$.

CONCLUSIONS: Cytokine levels were higher during the open approach than laparoscopic procedure. High levels of RBF during nephrectomy and transplantation improve early graft function while low levels of RBF and high levels ol IL-2 during nephrectomy induce delayed graft function.

Keywords: Cytokines. Transplantation. Pig model.

\section{INTRODUCCIÓN}

La modificación del perfil del donante renal, el aumento del número de pacientes en lista de espera para trasplante y las cifras alcanzadas de injerto procedente de donante cadáver, exigen el desarrollo del trasplante renal (TR) procedente de donante vivo.

La posibilidad de obtener un riñón mediante nefrectomía laparoscópica de un donante vivo (NLDV) es una realidad: ha incrementado el índice de donaciones (1), es una técnica menos invasiva para el donante que la nefrectomía abierta, lo que permite una menor estancia hospitalaria, menor analgesia en el postoperatorio y una incorporación más rápida a la actividad cotidiana.
Dependiendo del tipo de abordaje quirúrgico, abierto o laparoscópico, los niveles de citocinas circulantes presentan notables diferencias (2-17): Kristiansson y cols. (18), en su trabajo realizado sobre pacientes sometidos a colecistectomía abierta y laparoscópica, evidencian niveles de interleucinas (IL), sobre todo IL-6 menores en el grupo laparoscópico. Estos resultados se confirman por otros grupos que también encuentran valores de IL significativamente superiores durante la colecistectomía abierta frente a la laparoscópica (19-27).

Fornara y cols. (24), en su estudio experimental con cerdos, evidencian que los niveles de interleucinas durante y tras la nefrectomía abierta, eran significativamente superiores comparados con la nefrectomía laparoscópica. Otros autores encontraron los niveles de IL, concretamente de IL-6, proporcionales al daño tisular en estudios tanto clínicos como experimentales $(12,13,15,26,27)$.

Así, las citocinas no parecen tener un papel relevante en procesos de cirugía menor. Pero en procesos mayores, como la nefrectomía, la menor agresión quirúrgica que supondría la laparoscopia frente a la cirugía abierta, tendría relación con una reacción sistémica de fase aguda menos agresiva, con menor respuesta inmunológica, endocrina, metabólica y de neurotransmisores. Estos hallazgos estarían en consonancia con lo publicado por otros grupos $(26,28,29)$.

La lesión de isquemia-reperfusión tiene una gran importancia en el trasplante renal. La respuesta inflamatoria inducida por ésta, es determinante en el daño tisular y en el fracaso funcional del órgano $(30,35)$ y se caracteriza por el inicio de una cascada de citocinas proinflamatorias $(36,37)$ expresión de moléculas de adhesion (38) e infiltración celular (34, 39-41).

Estudios recientes muestran, que además del proceso inflamatorio, la muerte celular por apoptosis se incrementa durante el síndrome de isquemia-reperfusión (42-44).

Por tanto, la extensión del daño por isquemia-reperfusión inducido por la cascada inflamatoria y la apoptosis, viene determinada por el balance entre los distintos mediadores pro y anti-inflamatorios. Similar a como ocurre en el shock séptico experimental (45), donde la administración exógena de IL-10 tiene un efecto protector, también se demuestra ese efecto beficioso en el síndrome de isquemia-reperfusión a nivel experimental $(46,47)$ : Daemen y cols. (48) en línea con trabajos previos (41) demuestran en su estudio experimental con ratas, que la produc- 
ción endógena de IL-10 limita el del daño tisular y el empeoramiento de la función renal.

En relación al papel jugado por las citocinas en la función del trasplante renal, Kaminska y cols. (44) publicaron un significativo incremento de la expresión de IL-6 estudiada en la biopsia renal de aquellos riñones trasplantados, dependiendo del tiempo de isquemia fría sufrido por el injerto procedente de cadáver. La función posterior de ese riñón estaría influenciada por esas reacciones inflamatorias que se iniciarían tras la muerte cerebral del donante.

Deng y cols. (49) en su estudio experimental con ratas, demuestran que la administración de IL-10 al receptor reducía los efectos de la necrosis tubular aguda producida por la administración de cisplatino, y mejoraba la función renal al $2^{\circ}, 3^{\circ}$ y $5^{\circ}$ día del trasplante suministrada sóla o en combinación. El efecto de la IL-10 venía producido por la inhibición de la producción de factor de necrosis tumoral (TNF), de las moléculas de adhesión y de las sintetasa de óxido nítrico (NO), así como por la inhibición de la apoptosis. Más recientemente, basándose también en rata para sus trabajos experimentales, los trabajos de Chen y cols. (50) y Zhang W. y cols. (51) evidencian la mejora de la función del injerto renal tratados con IL-10 y Atorvastatina, respectivamente.

El objetivo de este estudio, basado en un modelo de trasplante renal experimental en cerdo, con injerto de donante vivo extraído mediante nefrectomía abierta y laparoscópica, es doble: en primer lugar, analizar comparativamente en ambos grupos el papel de distintas citocinas (IL-2, IL-6, IL-10 y TNF) como marcadores de invasividad quirúrgica tanto durante el procedimiento de extracción como de trasplante renal. En segundo lugar, analizar comparativamente la relación de los niveles de dichas citocinas con flujo sanguíneo renal (FSR) durante la nefrectomía, con el síndrome de isquemia-reperfusión y en la evolución funcional del injerto.

\section{MATERIAL Y MÉTODOS}

En nuestro modelo, se realizó la nefrectomía laparoscópica del donante vivo, y posteriormente autotrasplante ortotópico.

Los animales de estudio fueron 30 cerdos de raza ibérica, cuyo peso medio fue de $22.6 \pm 3,2 \mathrm{Kg}$ (Rango $19-31 \mathrm{Kg}$ ). Se estudiaron dos grupos de 15 cerdos cada uno:

- GRUPO ABIERTO ( $n=15$ cerdos). Utilizado como "GRUPO CONTROL" en el que la nefrectomía se realizó por cirugía abierta convencional.
- GRUPO LAP ( $n=15$ cerdos). Utilizado como "GRUPO ESTUDIO" en el que la nefrectomía se practicó por vía laparoscópica.

\section{Diseño del estudio}

Se realizó en todos los animales la premedicación con Ketamina intramuscular $(10 \mathrm{mg} / \mathrm{Kg})$ e inducción anestésica con Tiopental sódico intravenoso $(10 \mathrm{mg} / \mathrm{Kg})$ y Atropina $(0,01 \mathrm{mg} / \mathrm{Kg})$. Se procedió a la intubación endotraqueal y ventilación controlada del animal. La anestesia se mantuvo con Halotano al 0,9-1,25\% y $\mathrm{N}_{2} \mathrm{O}$ mezclado con $\mathrm{O}_{2}$. La analgesia intraoperatoria se realizó con Fentanilo a dosis de $50 \mu \mathrm{g} /$ hora. Se administró de forma preoperatoria Cefazolina 1 gramo intravenoso en dosis única. La hidratación del animal durante la cirugía se realizó mediante la administración de suero glucosalino a dosis de $10 \mathrm{ml} / \mathrm{Kg} / \mathrm{hora}$.

Durante todo el procedimiento los animales permanecieron con monitorización electrocardiográfica (derivaciones II y IV) y hemodinámica contínua, mediante la colocación de catéter vascular en la arteria y la vena femoral.

La nefrectomía se realizó en el grupo abierto mediante incisión de lumbotomía izquierda bajo la décimo-segunda costilla y en el grupo LAP mediante abordaje laparoscópico transperitoneal e insuflación con $\mathrm{CO}_{2}$ para mantener una presión intrabdominal (PIA) constante de $15 \mathrm{mmHg}$. El injerto fue perfundido con Eurocollins y preservado en isquemia fría a $4^{\circ} \mathrm{C}$ durante 24 horas.

Se practicó nefrectomía derecha abierta en los 30 casos, a través de una pequeña incisión de lumbotomía derecha extraperitoneal, y a continuación se realizó el autotrasplante ortotópico del riñón izquierdo en la fosa lumbar derecha del mismo animal, llevando a cabo la anastomosis término-terminal con sutura contínua $180^{\circ}$ con monofilamento irreabsorvible Prolene $7 / 0$ de la vena y arteria renales.

Por último, el sacrificio se realizó el $7^{\circ}$ día, mediante la inyección de cloruro potásico $(20 \mathrm{mEq})$ por vía intravenosa.

\section{Determinaciones analíticas}

Durante la fase de extracción, las muestras de sangre (IL, TNF y Creatinina plasmática) se tomaron a través del catéter central colocado en la vena femoral derecha en los dos grupos: basal (previo al comienzo de la nefrectomía izquierda) y a los a los 60 minutos de inicio de la cirugía tanto abierta como laparoscópica. 
Durante la fase de trasplante, en ambos grupos las determinaciones de sangre se realizaron al inicio y tras finalizar el autotrasplante ortotópico, y los días $1^{\circ}, 3^{\circ}, 5^{\circ}$ y $7^{\circ}$ del postoperatorio.

\section{Medidas del FSR}

Las medidas de FSR se obtuvieron mediante colocación del transductor de la sonda electromagnética alrededor de la arteria renal.

Durante la fase de extracción, se practicó en el grupo abierto determinación durante la nefrectomía izquierda abierta una vez que el FSR se estabilizó, y en el grupo laparoscópico determinación tanto basal, como a la hora de insuflación.

Durante la reperfusión, se realizó tras finalizar las anastomosis vasculares en ambos grupos y habiendo desclampado los vasos, a los 1, 5, 10, 20, 30, y 60 minutos.

\section{Análisis estadístico de los resultados}

Como estimador de la tendencia central de las variables se utilizó la media, y como estimador de la dispersión se empleó la desviación estándar. Para comparar la diferencia entre las medias, se utilizó el test de la t de Student.

IL-2

$\mathrm{pg} / \mathrm{ml}$

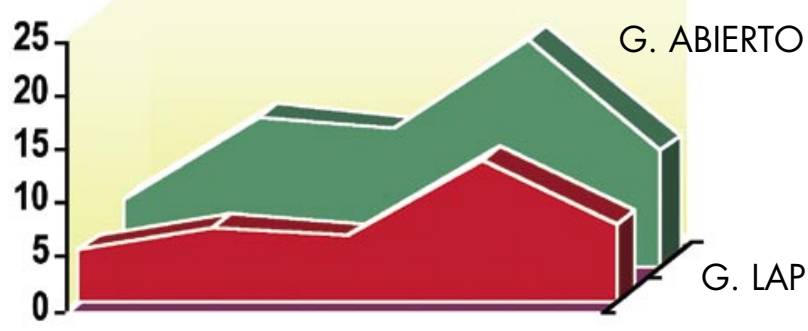

BASAL $1 \mathrm{H} \quad 24 \mathrm{H}$ POSTR $5^{\circ} \mathrm{D}$

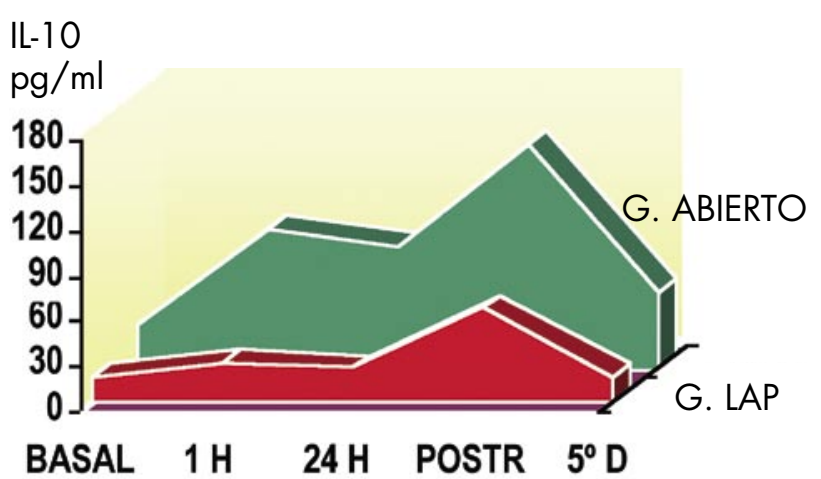

Para el estudio de la asociación entre las variables se emplearon modelos de regresión lineal múltiple:

- Para estudiar la asociación entre el FSR durante la nefrectomía y el nivel de citocinas a la hora de inicio de la nefrectomía en ambos grupos, el valor de FSR actuó como variable dependiente y el nivel de citocinas como variable independiente o predictora.

- Para estudiar la asociación entre el FSR de revascularización y el nivel de citocinas postTR en ambos grupos, se procedió como en el apartado anterior.

- Para estudiar la asociación entre la función del injerto postTR, con el FSR durante la nefrectomía y el nivel de citocinas en la primera hora de la cirugía de extracción en ambos grupos, actuó como variable dependiente la $\mathrm{Cr}$ plasmática del primer y séptimo día postTR, y como variables independientes o predictoras, el grupo, el FSR y el nivel de citocinas. Las variables se incorporaron al modelo por el método introducir.

- Para estudiar la asociación entre la función del injerto al primer y séptimo día postTR, con el FSR tras la revascularización y el nivel de citocinas postTR en

IL-6

$\mathrm{pg} / \mathrm{ml}$

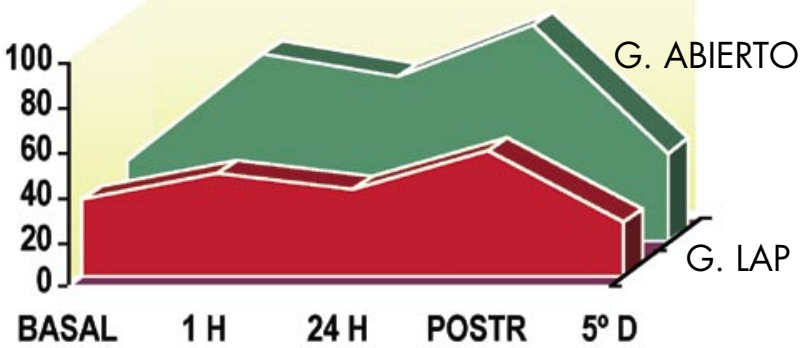

$\mathrm{TNF}$

$\mathrm{pg} / \mathrm{ml} \quad$ G. ABIERTO

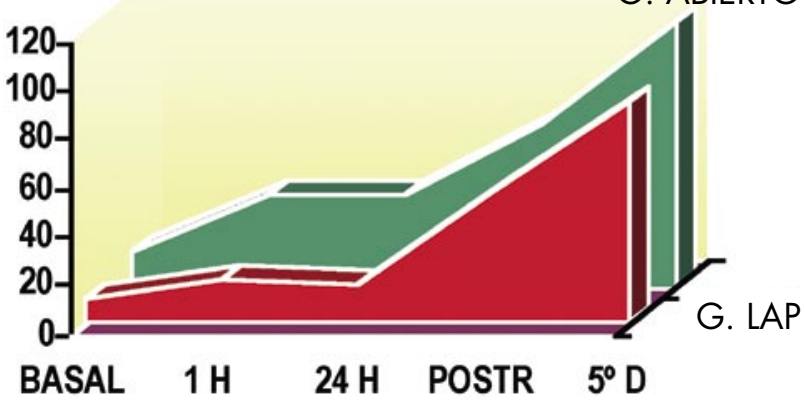

FIGURAS 1,2,3 y 4. Niveles de IL-2, IL-6, IL-10 y TNF basal, 1 hora tras el inicio de la nefrectomía, a las 24 horas del período de isquemia fría (preTR), postTR y 5 día postTR. 
ambos grupos, se procedió como en el apartado anterior.

Para todas las comparaciones se empleó un nivel de significación estadística del $95 \%$.

\section{RESULTADOS}

PAPEL DE LAS CITOCINAS EN LA CIRUGÍA DE LA EXTRACCIÓN Y DEL TR

Los niveles de citocinas fueros significativamente superiores en todos los momentos del estudio (extracción, revascularización y postrasplante) en el grupo abierto que en grupo LAP (Figuras 1, 2, 3 y 4, y Tablas I, II, III y IV).

\section{ASOCIACIÓN ENTRE EL FSR Y LOS NIVELES DE Cl- TOCINAS DURANTE LA FASE DE EXTRACCIÓN}

Análisis comparativo del FSR entre la nefrectomía abierta y la nefrectomía laparoscópica.

Los animales sometidos a nefrectomía izquierda laparoscópica sufrieron un descenso del $69 \%$ del FSR medio respecto al FSR medio del grupo abierto. La diferencia fue significativa $(p<0,001)$. (Figura 5 y Tabla V).

Análisis comparativo de los niveles de IL-2, IL 6, IL-10 y TNF entre la nefrectomía abierta y laparoscópica.

Los niveles de IL-2, IL 6, IL-10 y TNF medidos a la hora de inicio de la extracción renal fueron significativamente superiores en el grupo ABIERTO que en el grupo LAP $(p<0,001)$. (Figura 6 y Tabla VI).

TABLAS I, II, III Y IV. ESTUDIO COMPARATIVO DE LOS NIVELES DE IL-2, IL-6, IL-1O Y TNF DURANTE LA CIRUGÍA DE EXTRACCIÓN Y REVASCULARIZACIÓN DEL INJERTO RENAL OBTENIDO MEDIANTE NEFRECTOMÍA ABIERTA Y LAPAROSCÓPICA.

\begin{tabular}{|c|c|c|c|}
\hline $\begin{array}{c}\text { IL-2 } \\
\mathrm{pg} / \mathrm{ml}\end{array}$ & $\mathrm{G}$. ABIERTO & G. LAP & \\
\hline $\mathrm{BASAL}$ & $6,2 \pm 0,5$ & $5,0 \pm 0,5$ & $\mathrm{NS}$ \\
\hline $1 \mathrm{H}$ & $13,9 \pm 1,1$ & $6,8 \pm 0,6$ & $<0,001$ \\
\hline $24 \mathrm{H}$ & $12,7 \pm 1,0$ & $6,0 \pm 0,5$ & $<0,001$ \\
\hline POST-TR & $21,2 \pm 1,8$ & $13,1 \pm 1,1$ & $<0,001$ \\
\hline $5 \circ \mathrm{d}$ & $10,9 \pm 0,9$ & $7,1 \pm 0,5$ & $<0,001$ \\
\hline
\end{tabular}

\begin{tabular}{|c|c|c|c|}
\hline $\begin{array}{c}\text { IL-6 } \\
\text { pg/ml }\end{array}$ & $\begin{array}{c}\text { G. ABIERTO } \\
n=15\end{array}$ & $\begin{array}{l}\text { G. LAP } \\
n=15\end{array}$ & $\mathbf{p}$ \\
\hline BASAL & $36,0 \pm 1,6$ & $34,4 \pm 1,3$ & NS \\
\hline $1 \mathrm{H}$ & $84,4 \pm 2,5$ & $46,2 \pm 2,3$ & $<0,001$ \\
\hline $24 \mathrm{H}$ & $74,4 \pm 2,2$ & $39,0 \pm 1,1$ & $<0,001$ \\
\hline POST-TR & $97,1 \pm 3,8$ & $56,6 \pm 3,7$ & $<0,001$ \\
\hline $5^{\circ} \mathrm{d}$ & $39,9 \pm 2,0$ & $24,6 \pm 1,9$ & $<0,001$ \\
\hline
\end{tabular}

\begin{tabular}{|c|c|c|c|}
\hline $\begin{array}{c}\text { IL-10 } \\
\mathrm{pg} / \mathrm{ml}\end{array}$ & $\begin{array}{c}\text { G. ABIERTO } \\
\mathrm{n}=15\end{array}$ & $\begin{array}{c}\text { G. LAP } \\
\mathrm{n}=15\end{array}$ & $\mathbf{p}$ \\
\hline $\mathrm{BASAL}$ & $28,4 \pm 3,2$ & $16,5 \pm 2,5$ & $\mathrm{NS}$ \\
\hline $1 \mathrm{H}$ & $92,8 \pm 12,6$ & $26,1 \pm 2,4$ & $<0,001$ \\
\hline $24 \mathrm{H}$ & $80,6 \pm 12,9$ & $22,8 \pm 3,0$ & $<0,001$ \\
\hline POST-TR & $148,7 \pm 20,5$ & $62,5 \pm 7,9$ & $<0,001$ \\
\hline $5^{\circ} \mathrm{d}$ & $50,4 \pm 6,8$ & $16,4 \pm 3,0$ & $<0,001$ \\
\hline
\end{tabular}

\begin{tabular}{|c|c|c|c|}
\hline $\begin{array}{c}\text { TNF } \\
\mathrm{pg} / \mathrm{ml}\end{array}$ & $\begin{array}{c}\text { G. ABIERTO } \\
\mathrm{n}=15\end{array}$ & $\begin{array}{c}\text { G. LAP } \\
\mathrm{n}=15\end{array}$ & $\mathbf{p}$ \\
\hline BASAL & $14,3 \pm 2,3$ & $10,5 \pm 1,2$ & $\mathrm{NS}$ \\
\hline $1 \mathrm{H}$ & $38,5 \pm 4,8$ & $17,6 \pm 2,1$ & $<0,001$ \\
\hline $24 \mathrm{H}$ & $38,6 \pm 5,8$ & $16,8 \pm 2,1$ & $<0,001$ \\
\hline POST-TR & $67,4 \pm 6,3$ & $53,9 \pm 9,0$ & $<0,001$ \\
\hline $5 \circ \mathrm{d}$ & $109,9 \pm 9,7$ & $91,7 \pm 10,4$ & $<0,001$ \\
\hline
\end{tabular}




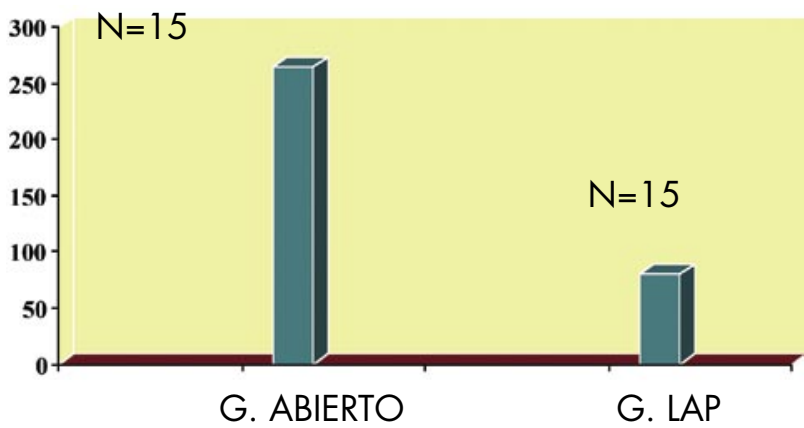

FIGURA 5. Modificaciones del FSR medio durante la primera hora de la nefrectomía abierta y laparoscópica.

Asociación entre el FSR y los niveles de citocinas durante la fase de extracción.

A continuación, se estudió la asociación entre el FSR (variable dependiente) y los niveles plasmáticos de citocinas (variables predictoras) una hora después del inicio de la nefrectomía, de modo comparativo entre el grupo ABIERTO y el grupo LAP.

Se puede concluir, que existe una ausencia de asociación entre el FSR durante la nefrectomía abierta o laparoscópica, y los niveles de IL-2 $(p=0,498)$, IL-6 $(p=0,117)$, IL-10 $(p=0,081)$ y TNF $(p=0,644)$.

\section{ASOCIACIÓN ENTRE EL FSR Y LOS NIVELES DE CI- TOCINAS DURANTE LA REPERFUSIÓN.}

Sindrome de isquemia-reperfusión. Análisis comparativo del FSR postdesclampaje entre nefrectomía abierta y laparoscópica.

La influencia de la nefrectomía laparoscópica en el síndrome de isquemia reperfusión, se analizó en base al análisis comparativo del FSR tras la revascularización del injerto renal al finalizar el autotrasplante de modo comparativo entre la cirugía

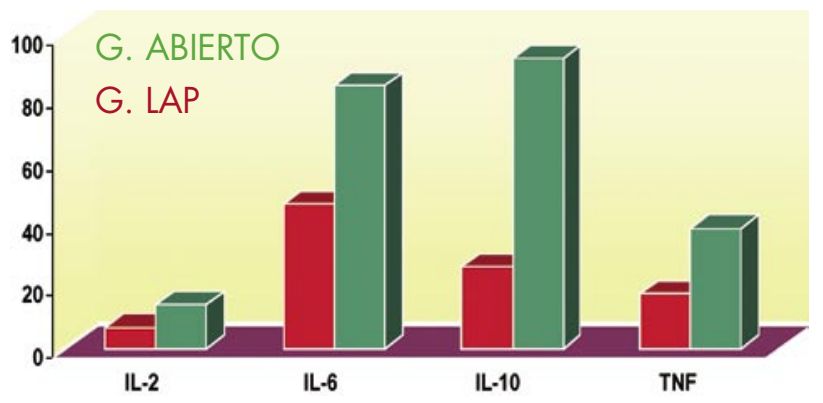

FIGURA 6. Niveles de citocinas obtenidos a la hora de inicio de la nefrectomía en ambos grupos.
TABLA V. FSR MEDIO DURANTE LA PRIMERA HORA DE LA NEFRECTOMIÁA IZQUIERDA EN AMBOS GRUPOS.

\begin{tabular}{|l|l|c|c|}
\hline & $\begin{array}{l}\text { G. ABIERTO } \\
\mathrm{n}=15\end{array}$ & $\begin{array}{c}\text { G. LAP } \\
\mathrm{n}=15\end{array}$ & $\mathrm{P}$ \\
\hline $\begin{array}{l}\text { FSR MEDIO } \\
\mathrm{ml} / \mathrm{min}\end{array}$ & $262,0 \pm 3,0$ & $80,0 \pm 2,7$ & $<0,001$ \\
\hline
\end{tabular}

abierta y laparoscópica tras el desclampaje. (Figura 7 y la Tabla VII).

El análisis comparativo del FSR en la $1^{\underline{a}}$ hora postTR objetivó:

- Una disminución significativa del FSR medio durante la primera hora en el grupo de laparoscopia frente al de cirugía abierta $(p<0,001)$.

- Una reducción del FSR en los primeros 5 minutos que es más acusado en el grupo con nefrectomía laparoscópica que con nefrectomía abierta $146 \pm$ $1,3 \mathrm{ml} / \mathrm{min}$ vs $80 \pm 1,6 \mathrm{ml} / \mathrm{min}$ a los 5 minutos; $\mathrm{p}<$ $0.001)$.

- Una recuperación progresiva del FSR durante la $1^{\underline{a}}$ hora, que es más lenta para el grupo LAP.

Análisis comparativo de los niveles de IL-2, IL-6, IL-10 y TNF postrasplante entre la nefrectomía abierta y laparoscópica.

Los niveles de IL-2, IL-6, IL-10 y TNF postrasplante, fueron significativamente superiores en el grupo ABIERTO frente al grupo LAP ( $p<0,001)$. (Fig. 8 y Tabla VIII).

TABLA VI. NIVELES DE IL-2, IL-6, IL-10 Y TNF OBTENIDOS A LA HORA DE INICIO DE LA CIRUGÍA EN EL GRUPO ABIERTO Y LAP.

\begin{tabular}{|l|l|c|c|}
\hline $\begin{array}{c}\text { Citocinas } \\
(\mathbf{1 ~ h}) \\
\mathbf{p g} / \mathbf{m l}\end{array}$ & $\begin{array}{c}\text { G. ABIERTO } \\
\mathrm{n}=15\end{array}$ & $\begin{array}{c}\text { G. LAP } \\
\mathrm{n}=15\end{array}$ & $\mathbf{p}$ \\
\hline $\mathrm{IL}-2$ & $13,9 \pm 1,1$ & $6,8 \pm 0,6$ & $<0,001$ \\
\hline $\mathrm{IL}-6$ & $84,4 \pm 2,5$ & $46,2 \pm 2,3$ & $<0,001$ \\
\hline $\mathrm{IL}-10$ & $92,8 \pm 12,6$ & $26,1 \pm 2,4$ & $<0,001$ \\
\hline TNF & $38,5 \pm 4,8$ & $17,6 \pm 2,1$ & $<0,001$ \\
\hline
\end{tabular}




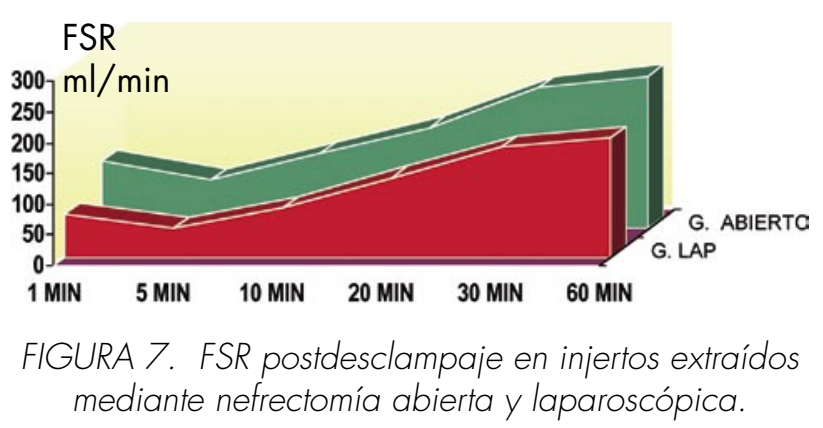

Asociación entre el FSR y los niveles de citocinas durante la reperfusión.

Se estudió la asociación entre el FSR a los 5 min de la reperfusión en ambos grupos y el nivel de citocinas plasmáticas postTR.

El análisis de regresión lineal múltiple, demostró:

- Existía una correlación significativa $\left(R^{2} 0,48 ; p=\right.$ $0,02)$ entre el FSR y el nivel de IL-10 postTR .

- Existía una ausencia de asociación entre el FSR y los niveles de IL-2 ( $\left.R^{2} 0,14 ; p=0,337\right)$, IL-6 $\left(R^{2} 0,18\right.$; $p=0,302)$ y $T N F\left(R^{2} 0,10 ; p=0,814\right)$ postTR.

\section{ASOCIACIÓN ENTRE LA FUNCIÓN DEL INJERTO Y EL NIVEL DE CITOCINAS Y FSR DURANTE LAS FASES DE EXTRACCIÓN Y REVASCULARIZACIÓN.}

\section{Evolución funcional del injerto. Análisis comparativo} entre nefrectomía abierta y laparoscópica.

Los niveles de $\mathrm{Cr}$ medidos los días 1, 3, 5, y 7 postrasplante descendieron progresivamente desde 1,3 a $0,8 \mathrm{mg} / \mathrm{dl}$ en el grupo ABIERTO, y de 2 a 1,1 $\mathrm{mg} / \mathrm{dl}$ en el grupo LAP. La diferencia entre ambos grupos fue significativa $(p<0,001)$.(Figura 9 y la Tabla IX).

Asociación entre la función del injerto y el nivel de citocinas y FSR durante las fases de extracción y revascularización.

Se analizó la influencia en la función del injerto en el postTR $(\mathrm{Cr}$ del primer día y $\mathrm{Cr}$ del séptimo día) de las siguientes variables:

1. FSR durante la extracción.

2. FSR durante la revascularización.

3. Citocinas durante la nefrectomía (1 hora).

4. Citocinas en el postTR (final del autoTR).

3.1. Fase de extracción. Función del injerto el primer día.

Se analizó la influencia en la $\mathrm{Cr}$ del primer día postTR, del FSR y los niveles de citocinas plasmáticas durante la nefrectomía.

El estudio de regresión lineal múltiple demostró:

- Existía una correlación significativa $\left(R=0,831, R^{2}=\right.$ $0,691, p=0,025)$ entre el valor de Cr del primer día postTR y el FSR e IL-2.

- Existía una ausencia de asociación entre el valor de $\mathrm{Cr}$ del primer día postTR y los niveles de IL-6 $(p=0,902)$, IL-10 $(0,761)$ y TNF $(p=0,983)$.

\subsection{Fase de extracción. Función del injerto al séptimo} día.

Se analizó la influencia en la $\mathrm{Cr}$ al séptimo día postTR, del FSR y los niveles de citocinas plasmáticas durante la nefrectomía.

\section{TABLA VII. VALORES DE FSR POSTDESCLAMPAJE DE LOS INJERTOS RENALES OBTENIDOS POR VÍA ABIERTA Y} LAPAROSCÓPICA.

\begin{tabular}{|c|c|c|c|c|}
\hline & TIEMPO (min) & $\begin{array}{c}\text { G. ABIERTO } \\
\mathrm{n}=15\end{array}$ & $\begin{array}{c}\text { G. LAP } \\
\mathrm{n}=15\end{array}$ & p \\
\hline \multirow{4}{*}{$\begin{array}{c}\text { FSR } \\
\text { POSTDESCLAMPAJE } \\
\text { (ml/min) }\end{array}$} & 1 & $111 \pm 1,7$ & $70 \pm 1,7$ & $<0,001$ \\
\cline { 2 - 5 } & 5 & $80 \pm 1,6$ & $46 \pm 1,3$ & $<0,001$ \\
\cline { 2 - 5 } & 10 & $123 \pm 1,9$ & $80 \pm 1,6$ & $<0,001$ \\
\cline { 2 - 5 } & 30 & $165 \pm 2,1$ & $130 \pm 1,4$ & $<0,001$ \\
\cline { 2 - 5 } & 60 & $230 \pm 2,5$ & $180 \pm 1,9$ & $<0,001$ \\
\cline { 2 - 5 } & FSR MEDIO & $159,7 \pm 6,6$ & $117,0 \pm 5,7$ & $<0,001$ \\
\hline & & $249 \pm 2,5$ & $195 \pm 1,8$ & $<0,001$ \\
\hline
\end{tabular}




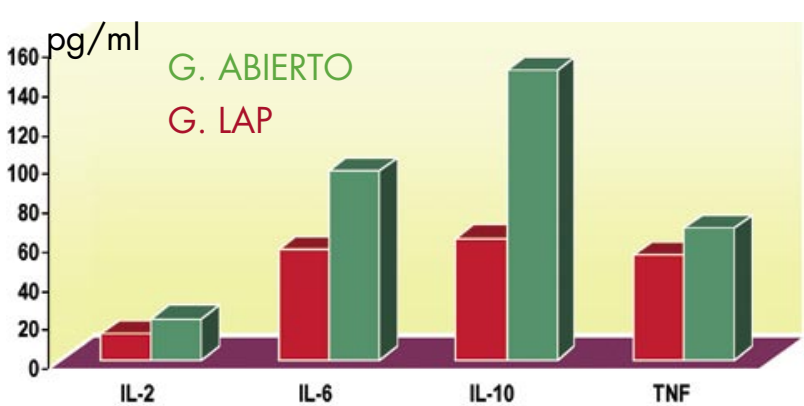

FIGURA 8. Valores de IL-2, IL-6, IL 10 y TNF tras la revascularización del injerto en el grupo ABIERTO y grupo LAP.

El estudio de regresión lineal múltiple demostró:

- Existía una correlación significativa $\left(R=0,685, R^{2}=\right.$ $0,469, p=0,015)$ entre el valor de Cr al séptimo día del TR y el nivel de IL-2.

- Existía una ausencia de asociación entre la función del injerto el séptimo día, el FSR $(p=0,194)$, y el nivel de IL-6 $(p=0,325)$, IL-10 $(p=0,580)$ y TNF $(p=$ $0,730)$.

\subsection{Fase de revascularización. Función del injerto el primer día.}

Se estudió la influencia en la función del injerto el primer día postTR, del FSR de la revascularización, y el nivel de citocinas postTR.

El estudio de regresión lineal múltiple demostró:

- Existía una correlación significativa $\left(R=0,784, R^{2}=\right.$ $0,614, p<0,0001$ ) entre el valor de Cr el primer día postTR y el FSR de revascularización.

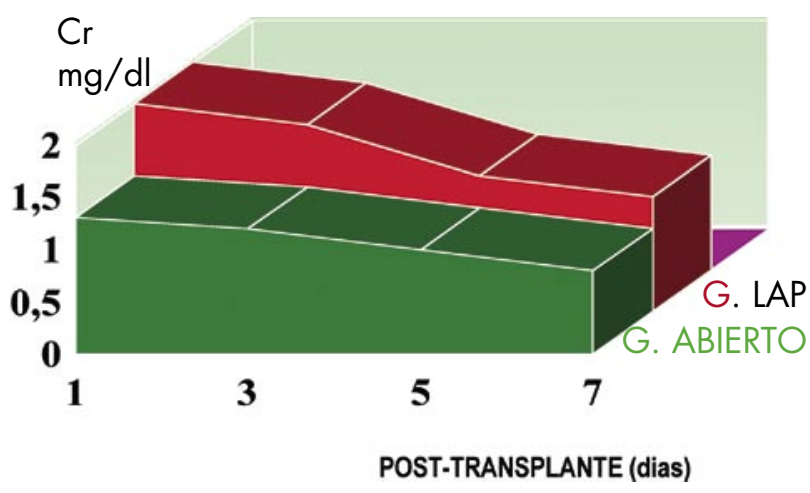

FIGURA 9. Análisis comparativo de los valores de Cr en el postrasplante de los injertos procedentes de nefrectomía laparoscópica y nefrectomía abierta.
TABLA VIII. VALORES DE CITOCINAS TRAS LA REVASCULARIZACIÓN DEL INJERTO EN AMBOS GRUPOS.

\begin{tabular}{|l|c|c|c|}
\hline $\begin{array}{c}\text { Citocinas } \\
(\mathbf{l ~ h}) \\
\mathbf{p g} / \mathbf{m l}\end{array}$ & $\begin{array}{c}\text { G. ABIERTO } \\
\mathrm{n}=15\end{array}$ & $\begin{array}{c}\text { G. LAP } \\
\mathrm{n}=15\end{array}$ & $\mathbf{p}$ \\
\hline $\mathrm{IL}-2$ & $21,2 \pm 1,8$ & $13,1 \pm 1,1$ & $<0,001$ \\
\hline IL-6 & $97,1 \pm 3,8$ & $56,6 \pm 3,7$ & $<0,001$ \\
\hline IL-10 & $148,7 \pm 20,5$ & $62,5 \pm 7,9$ & $<0,001$ \\
\hline TNF & $67,4 \pm 6,3$ & $53,9 \pm 9,0$ & $<0,001$ \\
\hline
\end{tabular}

- Existía una ausencia de asociación entre la función del injerto el primer día y los valores de IL-2 ( $p=$ $0,232)$, IL-6 $(p=0,471)$, IL-10 ( $p=0,732)$, y TNF ( $p=$ $0,843)$ postTR.

\subsection{Fase de revascularización. Función del injerto al séptimo día.}

Se estudió la influencia en la función del injerto al séptimo día, del FSR de la revascularización y el nivel de citocinas postTR.

El estudio de regresión lineal múltiple demostró:

- Existía una correlación significativa $\left(R=0,537, R^{2}=\right.$ $0,289, p=0,002$ ) entre la función del injerto al séptimo día postTR y el FSR de revascularización.

- Existía una ausencia de asociación entre el valor de Cr el séptimo día postTR y el nivel de IL-2 $(p=0,384)$, IL-6 (0,948), IL-10 ( $p=0,990)$, y TNF $(p=0,998)$.

\section{DISCUSIÓN}

Existen estudios retrospectivos comparando la NLDV frente a la nefrectomía abierta, que demuestran una función similar del injerto en ambos grupos al año del trasplante, pero con unos niveles más elevados de creatinina y mayor incidencia de necrosis tubular aguda (NTA) en el grupo de nefrectomía laparoscópica en las primeras semanas postTR $(52,53)$.

Si bien es verdad, que series extensas recientes no objetivan diferencias en la función de los injertos extraídos vía abierta versus laparoscópica (54).

Distintos mecanismos han sido implicados en la disfunción inicial de los injertos extraídos por vía laparoscópica, entre ellos el mayor tiempo de isquemia caliente y los efectos que el neumoperitoneo ejerce sobre el riñón $(54,55)$. Diversos estudios, tanto en 


\begin{tabular}{|c|c|c|c|c|}
\hline & $\begin{array}{c}\text { Postrasplante } \\
\text { (días) }\end{array}$ & $\begin{array}{c}\text { G. ABIERTO } \\
\mathrm{n}=15\end{array}$ & $\begin{array}{c}\text { G. LAP } \\
\mathrm{n}=15\end{array}$ & $\mathbf{p}$ \\
\hline \multirow{4}{*}{$\begin{array}{c}\text { Cr } \\
\mathbf{m g} / \mathbf{d l}\end{array}$} & Basal & $0,8 \pm 0,4$ & $0,7 \pm 0,0$ & $<0,001$ \\
\cline { 2 - 5 } & 1 & $1,3 \pm 0,1$ & $2,0 \pm 0,1$ & $<0,001$ \\
\cline { 2 - 5 } & 3 & $1,2 \pm 0,1$ & $1,8 \pm 0,1$ & $<0,001$ \\
\cline { 2 - 5 } & 5 & $1,0 \pm 0,1$ & $1,3 \pm 0,1$ & $<0,001$ \\
\cline { 2 - 5 } & 7 & $0,8 \pm 0,1$ & $1,1 \pm 0,1$ & $<0,001$ \\
\hline
\end{tabular}

modelos experimentales de animal grande $(56,57)$ como pequeño (58) han revelado con el neumoperitoneo, una disminución del FSR; lo que favorecería la oliguria y la NTA (59). Sin embargo, los efectos del neumoperitoneo sobre la función renal de los injertos renales extraídos por vía laparoscópica no ha sido aún completamente estudiada (60), estando algunos aspectos sometidos a controversia, entre ellos el papel modulador de las citocinas en el proceso de extracción y posterior trasplante, y su repercusión en la función del injerto.

Para llevar a cabo el estudio se eligió un modelo experimental y no clínico. De esta manera se tiene un control adecuado de todas las variables que intervienen. Además, se escogió un animal de experimentación grande, como el cerdo, que guarda una gran similitud con el humano. En el modelo del estudio, se realizó la nefrectomía laparoscópica del donante vivo, y posteriormente autotrasplante ortotópico. Todo ello difiere de la mayoría de los trabajos experimentales realizados hasta ahora, en los que se suelen medir el efecto del neumoperitoneo sobre los parámetros hemodinámicos y el FSR y niveles de citocinas en animales de experimentación pequeños (58,60-63). Además, el impacto del neumoperitoneo en el síndrome de isquemia reperfusión y en la evolución funcional del injerto extraído por vía laparoscópica, apenas se ha realizado en el modelo experimental animal, sino que en la literatura se refleja en las series de casos clínicos de los principales centros donde se realiza la NLDV (64-75). En definitiva, se ha intentado reproducir, con la máxima similitud posible y reduciendo al máximo el número de variables, aquella situación clínica que se daría en el humano. Como único factor criticable, que no se reproduce exactamente en el TR con donante vivo en el humano, se encuentra el someter el injerto a un período de isquemia fría de 24 horas. Esta circunstancia fue una exigencia del adiestramiento laparoscópico inicial del grupo, de la puesta a punto del modelo experimental y de la exigencia de estudiar las modificaciones inducidas por distintos ciclos de insuflación y desinsuflación. En cualquier caso, es un factor común al TR de injertos obtenidos tanto por vía abierta como laparoscópica.

La respuesta inmunohumoral inducida por la cirugía de la extracción, está mediada por citocinas. Se pueden incluir en ese grupo las IL, los interferones (IFN), los factores estimuladores de colonias (CSF), el TNF, los factores de crecimiento y las quimiocinas (citocinas quimiotácticas).

Las IL son un extenso grupo de citocinas, desde IL-1 a IL-18, que son producidas fundamentalmente por las células T, aunque los fagocitos mononucleares y algunas células tisulares también producen algunas de ellas. Ejercen funciones muy variadas, pero la misión de la mayoría de ellas es inducir la multiplicación y diferenciación de otras células. Cada IL actúa sobre un tipo de célula concreto, que expresa los receptores adecuados para ella (6).

LA IL-2 es producida por las células T, CD4 ${ }^{+}$ sobre todo, aunque las $\mathrm{CD} 8+$ y los linfocitos grandes granulosos (LGG) también la producen. Actúa sobre un rango restringido de células, principalmente células $\mathrm{T}$ (de todos los tipos), para los que constituye el factor de crecimiento y activador más potente.

La IL-6, denominada inicialmente factor de diferenciación de las células B o factor estimulante de los hepatocitos, es producida en muchas células, incluídas las células $T$, los macrófagos, las células $B$, los fibroblastos y las células endoteliales. Actúa sobre la mayoría de las células, pero parece especialmente importante como inductor de la diferenciación de las células $B$ en células formadoras de anticuerpos y la inducción de la síntesis de proteínas de fase aguda. Induce la expre- 
sión del receptor de IL-2 así como la producción de IL-2 por estimulación de los linfocitos T (4).

La IL-10, producida por los linfocitos T, Th2 helper, denominada también factor inhibidor de la síntesis de citocinas, inhibe la producción de interferón gamma (INF $\gamma)$, la presentación de antígenos y la producción de IL-1, IL-6 y TNF por parte de los macrófagos, favoreciendo de este modo las respuestas de tipo Th2 y la activación de las células B.

La producción endógena de IL-10 es un aspecto importante de la respuesta antiinflamatoria que ocurre de forma natural, a través de la inhibición de TNF- $\alpha$, IL-1, IL-6, la producción de radicales libres, óxido nítrico (NO) y la expresión de moléculas de adhesión (5).

El TNF consta de dos subunidades; $\alpha$ producida por los macrófagos, linfocitos y mastocitos y la $\beta$ producida por linfocitos. Actúa activando a los macrófagos y granulocitos, aumentando la adherencia de los leucocitos al endotelio e induciendo la síntesis de proteínas de fase aguda (6).

El estudio evidencia que:

En primer lugar, que distintos mediadores podrían estar involucrados en el síndrome de isquemiareperfusión y en la disfunción de los injertos extraídos por laparoscopia. El análisis comparativo del nivel de citocinas (IL-2, IL-6, IL-10 y TNF) en ambos grupos, demostró ser significativamente superior en el grupo ABIERTO frente al grupo LAP (Figuras 1-4).

En segundo lugar, no existió correlación entre el FSR y los niveles de citocinas en la fase de extracción. Sin embargo, durante la fase de revascularización, se objetivó una correlación entre el nivel de IL-10 y la disminución del FSR al final del autoTR.

En tercer lugar, la función inicial del injerto se correlacionó con el FSR durante la nefrectomía, con el FSR postTR y el nivel de IL-2 durante la extracción. La función tardía del injerto se correlacionó con el FSR postTR y el nivel de IL-2 durante la extracción.

\section{Las citocinas parecen ser indicadores útiles de agresi- vidad quirúrgica.}

El acto quirúrgico provoca un daño tisular que conlleva la activación de monocitos y macrófagos que producen citocinas y otros mediadores, responsables de la reacción de fase aguda (2-7). Esta respuesta sería proporcional a la extensión del daño al tejido $(10-16,26,27)$.

Kristiansson y cols. (18), en su trabajo realizado sobre pacientes sometidos a colecistectomía abierta y laparoscópica, evidencian niveles de interleucinas, sobre todo IL-6 comparada con TNF, IL-1, cortisol y catecolaminas, menores en el grupo laparoscópico. Estos resultados se confirman por otros grupos que también encuentran valores de interleucinas significativamente superiores durante la colecistectomía abierta frente a la laparoscópica (19-23). Por el contrario, no se han evidenciado diferencias entre la histerectomía abierta y laparoscópica así como entre la herniorrafia abierta y laparoscópica $(76,77)$. Como describen Fornara y cols. (24) sólo en los casos de cirugía mayor parece existir una respuesta de fase aguda y parece que en estos casos es dónde la cirugía laparoscópica condiciona una invasividad quirúrgica significativamente menor.

Fornara y cols. (24), en su estudio experimental con cerdos, evidencian que los niveles de interleucinas durante y tras la nefrectomía abierta, eran significativamente superiores comparados con la nefrectomía laparoscópica. La elevación de IL-6 tras la nefrectomía bilateral laparoscópica era comparable a los niveles tras la nefrectomía laparoscópica unilateral. La IL-6 se mostraba como un parámetro útil a la hora de predecir las complicaciones postoperatorias y el fallo del órgano $(10,11,14,16)$.

En el modelo del estudio, se objetivó una elevación significativamente mayor de los niveles de todas las citocinas (IL-2, IL-6, IL-10 y TNF) durante la nefrectomía abierta que en la laparoscópica, pareciendo por tanto ser todas ellas buenos marcadores de la invasividad quirúrgica. En una segunda agresión quirúrgica 24 horas después, se comprueba que existe una nueva elevación de todas las citocinas que vuelve a ser superior para aquellos animales a los que la extracción se hizo mediante cirugía abierta. Sin embargo, es difícil discernir en esta segunda elevación que parte corresponde a la segunda agresión quirúrgica y que parte a la persistencia de los niveles altos inducidos por la nefrectomía debido a la distinta vida media de las diferentes citocinas.

Desde el punto de vista de la evolución de las citocinas en la secuencia quirúrgica de nuestro modelo experimental, parece haber dos comportamientos distintos. La IL-2 y TNF se elevan de modo inmediato tras la agresión quirúrgica, pero su vida media es corta y vuelven a la normalidad tempranamente. El segundo modelo de comportamiento, sería el de la IL-6 e IL-10 que si bien igualmente se elevan tras la nefrectomía y el autoTR, su normalización es más lenta ya que continúan siendo significativas las elevaciones entre los niveles al final de la nefrectomía y los del inicio y final del autoTR. Este hecho podría justificarse por una vida media más larga o una ele- 
vación más tardía y sostenida de las mismas tras la agresión quirúrgica.

\section{En relación a la influencia de la respuesta inmuno- humoral que la cirugía de la extracción tiene en el síndrome de isquemia reperfusión, esta circunstancia está escasamente analizada.}

Sin embargo, muchos estudios muestran que la respuesta inflamatoria inducida por la isquemiareperfusión es determinante en el daño tisular y en el fracaso funcional del órgano $(34,35)$.

La respuesta inflamatoria aguda iniciada por la isquemia-reperfusión se caracteriza por el inicio de una cascada de citocinas proinflamatorias $(36,37)$ expresión de moléculas de adhesión (38) e infiltración celular (39). Otros datos de la respuesta inflamatoria son menos agudos e incluyen la infiltración local por linfocitos T y macrófagos (34), así como los antígenos HLA $(40,41)$.

Estudios recientes muestran, que además del proceso inflamatorio, la muerte celular por apoptosis se incrementa durante el síndrome de isquemia-reperfusión (42-44). La extensión del daño por isquemiareperfusión inducido por la cascada inflamatoria y la apoptosis, viene determinada por el balance entre los distintos mediadores pro y anti-inflamatorios.

Daemen y cols. (48), demuestran en su estudio experimental, que la producción de IL-10 endógena es una parte natural de la respuesta inflamatoria que limita el efecto perjudicial de la cascada inflamatoria que tiene lugar tras la reperfusión postisquemia. Sus resultados muestran que aquellos riñones de animales tratados con anticuerpos anti-lL-10, tenían un incremento en los niveles de TNF- $\alpha$ con el consiguiente incremento del daño tisular y empeoramiento de la función renal.

Por tanto, desde un punto de vista conceptual, la administración de IL-10 exógena o de fármacos inductores de su producción en el síndrome de isquemia reperfusión puede ser valioso, no sólo para reducir el daño tisular mediado por neutrófilos y la apoptosis celular $(46,47)$ sino también prevenir el aumento de inmunogenicidad del injerto provocado por la expresión de moléculas del $\mathrm{CMH}$ de tipo I y II (78).

Similar a como ocurre en el shock séptico experimental (45), donde la administración exógena de IL-10 tiene un efecto protector. En la misma línea de la terapia del precondicionamiento isquémico (79), Oltean y cols. (80) demuestran en su estudio experimental de trasplante intestinal en ratas, una respuesta inflamatoria menor (menores niveles de IL-6 y una mejor función tanto hepática como renal) en aquellos injertos procedentes de donantes tratados previamente con tacrolimus.

Los resultados obtenidos en nuestro estudio están en consonancia con estos datos, ya que existe una correlación directa entre los niveles de IL-10 al final del autoTR y el FSR postrevascularización $\left(R^{2}=\right.$ $0,48, p=0,002$ ) (Figura 35) y éste es un factor determinante de la función inicial del injerto, tanto al primer como al séptimo día $\left(R^{2}=0,614, p<0,0001\right.$ y $R^{2}=0,289, p=0,002$ ). Por tanto, los niveles de IL10 durante el autoTR parecen jugar un cierto papel protector del injerto, atenuando el síndrome de isquemia reperfusión y mejorando la función del mismo durante la primera semana del TR.

En relación al papel de las citocinas en el postrasplante renal, se ha descrito que la producción de IL-2 juega un papel importante en la lesión por isquemia reperfusión y también lo hace en la patogénesis del rechazo agudo postTR.

Kaminska y cols. (44) publicaron un incremento significativo de la expresión de IL-6 estudiada en la biopsia renal de aquellos riñones trasplantados dependiendo del tiempo de isquemia fría sufrido por el injerto procedente de cadáver. La IL-6 que es esencial para la activación y proliferación de linfocitos $T$, posiblemente jugaría un papel importante en la patogénesis del rechazo agudo: la IL-6 induce la expresión del receptor de IL-2 y la producción de IL-2 por estimulación de los linfocitos T, así como la diferenciación de los linfocitos T citotóxicos. Concluyen su trabajo, indicando que la intensidad de los cambios inflamatorios tempranos que tienen lugar en el injerto a nivel tubular, se asocian con un mayor tiempo de isquemia fría. La función posterior de ese riñón estaría pues influenciada por esas reacciones inflamatorias que se iniciarían tras la muerte cerebral del donante.

Pero a largo plazo no parecen existir diferencias en cuanto a la inmunoshistoquímica de los injertos ni en su función renal ya sean extraídos vía abierta o laparoscópica: Hazebroek y cols. (60) en su estudio experimental con ratas, evaluó si durante la insuflación laparoscópica se producía una infiltración celular adicional de linfocitos $\mathrm{CD}^{+}{ }^{+}, \mathrm{CD} 8^{+}$, macrófagos, células dendríticas, células del HLA tipo II, moléculas de adhesión frente al injerto extraído mediante cirugía abierta. No se encontraron diferencias significativas a las 52 semanas del trasplante en los hallazgos inmunohistoquímicos ni en la función renal.

En síntesis:

En el presente estudio, tan sólo los niveles de IL-2 durante la extracción parecen influir de modo di- 
recto en la función inicial del injerto. De hecho, existe una curiosa correlación directa entre los niveles de IL-2 y las cifras de $\mathrm{Cr}$ al primer y séptimo día postTR. Esto es, a mayor producción de IL-2 en la extracción, peor función del injerto en el postTR inmediato, posiblemente como expresión de mayor invasividad quirúrgica y de mayor lesión tisular para el riñón.

Por otro lado, de modo indirecto ya ha sido descrito el papel aparentemente "protector" que los niveles de IL-10 durante el autoTR jugarían al condicionar un mejor FSR durante la revascularización, atenuando así el síndrome de isquemia-reperfusión.

Por tanto, los factores determinantes de la función del injerto en el postTR inmediato son básicamente los FSR durante la extracción y de IL-10 durante el TR. FSR bajos y niveles de IL-2 en la extracción altos, favorecen la disfunción del injerto, mientras que FSR altos y niveles de IL-10 altos durante el TR colaborarían a una mejor función del injerto en el postTR inmediato.

\section{CONCLUSIONES}

El abordaje laparoscópico durante la nefrectomía de donante vivo induce una menor respuesta inmunohumoral evaluada por los niveles de citocinas (IL-2, IL-6, IL-10 y TNF).

Los valores altos de FSR durante la extracción y el TR, y los niveles elevados de IL-10 durante el TR, mejoran la función del injerto en el postTR inmediato, mientras que valores de FSR bajos y niveles elevados de IL-2 durante la extracción afectan negativamente a la función del injerto durante la primera semana postrasplante.

\section{BIBLIOGRAFÍA Y LECTURAS RECOMENDADAS ( ${ }^{*}$ lectura de interés $y^{* *}$ lectura fundamental)}

1. SCHWEITZER, E.; WILSON, J.; JACOBS, S. y cols.: "Increased rates of donation with laparoscopic donor nephrectomy". Ann Surg., 232: 392, 2000.

2. HARRIS, B.H.; GELFAND, J.A.: "The immune response to trauma". Semin. Pediatr. Surg., 4: 77, 1995.

3. FAIST, E.; SCHINKEL, C.; ZIMMER, S.: "Update on the mechanism of immune suppression of injury and immune modulation”. World J. Surg., 20: 454, 1996.

*4. SCHLAG, G.; REDL, H.: "Mediators of injury and inflammation". World J. Surg., 20: 406, 1996.
5. BAUMANN, H.; GAULDIE, J.: "The acute phase response". Immunol Today, 15: 74, 1994.

*6. PANNEN, H.J.; ROBOTHAM, J.L.: "The acutephase response". New Horiz., 3: 183, 1995.

7. GABAY, C.; KUSHNER, I.: "Acute-phase proteins and other systemic responses to inflammation". $\mathrm{N}$. Engl. J. Med., 340: 448, 1999.

*8. LINARES QUEVEDO, A.I.; BURGOS REVILLA, F.J.; VILLAFRUELA SANZ, J.J. y cols.: "Análisis comparativo de las modificaciones hemodinámicas y del flujo sanguíneo renal (FSR) durante la nefrectomía abierta y laparoscópica. Modelo experimental". Actas Urol. Esp., 31: 382, 2007.

*9. BURGOS, F.J.; LINARES, A.; PASCUAL, J. y cols.: "Modifications of renal blood flow and serum interleukin levels induced by laparoscopic and open living donor nephrectomies for kidney transplant. An experimental study in pigs". Transplant. Proc., 37: 3676, 2005.

*10. OKA, Y.; MURATA, A.; NISHIJIMA, J. y cols.: "Circulating inteleukin-6 as a useful marker for predicting postoperative complications". Cytokine, 4: 298, 1992.

11. HOCH, R.C.; RODRÍGUEZ, R.; MANNING, T. y cols.: "Effects of accidental trauma con cytokine and endotoxin production". Crit. Care Med., 21: 839, 1993.

*12. BITTERMAN, H.; KINARTY, A.; LAZAROVICH, H. y cols.: "Acute release of cytokines is proportional to tissue injury induced by surgical trauma and shock in rats". J. Clin. Immunol., 11: 184, 1991.

13. CINAT, M.; WAXMAN, K.; VAZIRI, N.D. y cols.: "Soluble cytokine receptors and receptor antagonists are sequentially released after trauma". J. Trauma., 39: 112, 1995.

*14. ROUMEN, R.M.; HENDRIKS, T.; VAN DER VEN JONGEKRIG, J. y cols.: "Cytokine patterns in patients after major vascular surgery, hemorrhagic Soc, and severe blunt trauma. Relation with subsequent adult respiratory distress syndrome and multiple organ failure". Ann Surg., 218: 769, 1993.

*15. CRUICKSHANK, A.M.; FRASER, W.D.; BURNS, H.J. y cols.: "Response of serum interleukin-6 in patients undergoing elective surgery of varying severity". Clin. Sci., 79: 161, 1990.

*16. KRAGSBJERG, P.; HOLMBERG, H.; VIKERFORS, T.: "Serum concentrations on interleukin-6, tumour necrosis factor-alpha, and C-reactive protein in patients undergoing major operations". Eur. J. Surg., 161: 17, 1995.

17. CHRISTENSEN, T.; BENDIX, T.; KEHLET, H.: "Fatigue and cardiorespiratory function following abdominal surgery". Br. J. Surg., 69: 417, 1982.

*18. KRISTIANSSON, M.; SARASTE, L.; SOOP, M. y cols.: "Dimished interleukin-6 and C-reactive protein responses to laparoscopic versus open cholecystectomy". Acta Anaesthesiol. Scand., 43: 146, 1999.

19. REITH, H.B.; KAMAN, S.; MITTELKOTTER, O. y cols.: "Cytokine activation in patients undergoing open or laparoscopic cholecistectomy". Int. Surg., 82: 389, 1997. 
*20. JABERANSARI, M.T.; ROTH, E.; GAL, I. y cols.: "Inflammatory mediators and Surgical trauma regarding laparoscopic access: Acute phase response". Acta Chir. Hung., 36: 138, 1997.

21. BELLON, J.M.; MANZANO, L.; LARRAD, A. y cols.: "Endocrine and immune response to injury after open and laparoscopic cholecistectomy". Int. Surg., 83: 24, 1998.

22. JAKEWAYS, M.S.; MITCHELL, V.; HASHIM, I.A. y cols.: "Metabolic and inflammatory responses after open or laparoscopic cholecistectomy". Br. J. Surg., 81: 127, 1994.

*23. MARUSZYNSKI, M.; POJDA, Z.: "Interleukin 6 (IL-6) levels in the monitoring of surgical trauma. A comparison of serum IL- 6 concentrations inpatients treated by cholecistectomy via laparotomy or laparoscopy". Surg. Endosc., 9: 882, 1995.

**24. FORNARA, P.; DOEHN, C.; SEYFARTH, M. y cols.: "Why is urological laparoscopy minimally invasive?". Eur. Urol., 37: 241, 2000.

25. SAALMÜLLER, A.; BRYANT, J.: "Characteristics of porcine T lymphocytes and T-cell lines". Vet Immunopathol., 43: 45, 1994.

**26. FORNARA, P.; DOEHN, C.; FRICKE, L. y cols.: "Laparoscopic bilateral nephrectomy: Results in 11 renal transplant patients". J. Urol., 157: 445, 1997.

**27. FORNARA, P.; DOEHN, C.; FRICKE, L. y cols.: "Laparoscopy in renal transplant patients". Urology, 49: 521, 1997.

*28. DOEHN, C.; FORNARA, P.; FRICKE, L. y cols.: "Comparison of laparoscopic and open nephroureterectomy for benign disease". J. Urol., 159: 732, 1998.

29. PARRA, R.O.; PÉREZ, M.G.; BOULLIER, J.A. y cols.: "Comparison between standard flank versus laparoscopic nephrectomy for benign renal disease”. J. Urol., 153: 1171, 1995.

*30. COLLETTI, L.M.; KUNKEL, S.L.; WALZ, A. y cols.: "The role of c cytokine networks in the local liver injury following hepatic ischemia/reperfusion in the rat". Hepatology, 23: 506, 1996.

31. COLlETTI, L.M.; REMICK, D.G.; BURTCH, G.D. y cols.: "Role of tumor necrosis factor-alpha in the pathophysiologic alterations after hepatic ischemia/reperfusion injury in the rat". J. Clin. Invest., 85: 1936, 1990.

*32. COLLETTI, L.M.; KUNKEL, S.L.; WALZ, A. y cols.: "Chemokine expression during hepatic ische$\mathrm{mia} /$ reperfusion-induced lung injury in the rat: The role of epithelial neutrophil activating protein". J. Clin. Invest., 95: 134, 1995.

33. IOCULANO, M.; ALTAVILLA, D.; SQUADRITO, F. y cols.: "Tumor necrosis factor mediates Eselecting production and leucocyte accumulation in myocardial ischemia-reperfusion injury". Pharmacol Res., 31: 281, 1995.

*34. TAKADA, M.; NADEAU, K.C.; SHAW, G.D. y cols.: "The cytokine adhesion molecule cascade in ischemia/reperfusion injury of the rat kidney: inhibition by soluble P selecting ligand". J. Clin. Invest., 99: 2682, 1997.

35. VEDDER, N.B.; WINN, R.K.; RICE, C.L. y cols.:
"Inhibition of Leucocyte adherence by anti-CD18 monoclonal antibody attenuates reperfusion injury injury in the rabbit ear". Proc. Natl. Acad. Sci. USA, 87: 2643, 1990.

*36. HALLORAN, P.F.; HOMIK, J.; GOES, N. y cols.: "The injury response: a concept linking nonspecific injury, acute rejection, and long term transplant outcomes". Transplant Proc., 29: 79, 1997.

*37. HERSKOWITZ, A.; CHOI, S.; ANSARI, A. y cols.: "Cytokine mRNA expression in postischemic/reperfused myocardium”. Am. J. Pathol., 146: 419, 1995.

38. RABB, H.; MENDIOLA, C.C.; SABA, S.R. y cols.: "Antibodies to ICAM-1 protect kidneys in severe ischemic reperfusion injury". Biochem Biophys Res Commun., 211: 67, 1995.

*39. LINAS, S.L.; WHITENBURG, D.; PARSONS, P.E. y cols.: "Ischemia increases neutrophil retention and worsens acute renal failure: role of oxygen metabolites and ICAM 1". Kidney Int., 48: 1584, 1995.

*40. GOES, N.; HOBART, M.; RAMASSAR, V. y cols.: "Many forms of renal injury induce a stereotyped response with increased expression of MHC, IFN gamma, and adhesion molecules". Transplant Proc., 29: 1085, 1997.

*41. GOES, N.; URMSON, J.; VINCENT, D. y cols.: "Induction of major histocompatibility complex markers and inflammatory cytokines after ischemic injury to the kidney: lessons from interferon-gamma gene knockout mice". Transplant Proc., 27: 771, 1995.

42. RAAFAT, A.M.; MURRAY, M.T.; McGuire, T. y cols.: "Calcium blockade reduces renal apoptosis during ischemia reperfusion”. Shock, 8: 186, 1997.

*43. SHAH, K.A.; SHUREY, S.; GREEN, C.J.: “Apoptosis after intestinal ischemia-reperfusion injury: A morphological study". Transplantation, 64: 1393, 1997.

**44. KAMINSKA, D.; TYRAN, B.; MAZANOWSKA, A. y cols.: "Cytokine gene expression in kidney allograft donor biopsies after cold ischemia and reperfusion using in situ RT-PCR Analysis". Transplant Proc., 35: 2155, 2003.

*45. MARCHANT, A.; BRUYNS, C.; VANDENABEELE, P. y cols.: "Interleukin- 10 controls interferon-gamma and tumor necrosis factor production during experimental endotoxemia". Eur. J. Immunol., 24: 1167, 1994.

46. LANE, J.S.; TODD, K.E.; LEWIS, M.P.N. y cols.: "Interleukin-10 reduces the systemic inflammatory response in a murine model $\mathrm{f}$ intestinal ischemia/reperfusion". Surgery, 122: 288, 1997.

**47. ENGLES, R.E.; HUBER, T.S.; ZANDER, D.S. y cols.: "Exogenous human recombinant interleukin10 attenuates ischemia-reperfusion injury". J. Surg. Res., 69: 425, 1997.

**48. DAEMEN, M.; VAN DE VEN, M.; HEINEMAN, E. y cols.: "Involvement of endogenous interleukin-10 and tumor necrosis factor in renal ischemiareperfusion injury". Transplant, 67: 792, 1999.

*49. DENG, J.; KOHDA, Y.; CHIAO, H. y cols.: "Inter- 
leukin-10 inhibits ischemic and cisplatin-induced acute renal injury". Kidney Int., 60: 2118, 2001.

**50. CHEN, B.; KAPTURCZAK, M.H.; JOSEPH, R. y cols.: "Adeno-associated viral vector-mediated interleukin-10 prolongs allograft survival ina rat kidney transplantation model. Am. J. Transplant., 7: 1112, 2007.

*51. ZHANG, W.; LIU, M.; WU, Y. y cols.: "Protective effects of Atorvastatina on chronic allograft nephropathy in rats". J. Surg. Res., 2007.

*52. NOGUEIRA, J.; CANGRO, C.; FINK, J. y cols.: "Comparison of recipient renal outcomes with laparoscopic versus open live donor nephrectomy". Transplantation, 67: 722, 1999.

*53. RATNER, L.E.; MONTGOMERY, R.A.; MALEY, W.R. y cols.: "Laparoscopic live donor nephrectomy: The recipient". Transplantation, 69: 2319, 2000.

*54. SUNDARAM, C.P.; MARTIN, G.L.; GUISE, A. y cols.: "Complications after a 5-year experience with laparoscopic donor nephrectomy: The Indiana University experience”. Surg. Endosc., 21: 724, 2007.

*55. McDOUGALL, E.M.; MONK, T.G.; WOLF, J.S. JR. y cols.: "The effect of prolonged pneumoperitoneum on renal function in animal model". J. Am. Coll. Surg., 182: 317, 1996.

56. LONDON, E.; HO, H.; NEUHAUS, A.N.N. y cols.: "Effect of intravascular volume expansion on renal function during prolongued $\mathrm{CO} 2$ pneumoperitoneum". Ann. Surg., 231: 195, 2000.

57. HARMAN, R.K.; KRON, I.L.; McLACHLAN, H.D. y cols.: "Elevated intraabdominal pressure and renal function". Am. Surg., 196: 594, 1982.

58. KIRSCH, A.J.; HENSLE, T.W.; CHANG, D.T. y cols.: "Renal effects of $\mathrm{CO} 2$ insufflation: Oliguria and acute renal dysfunction in a rat pneumoperitoneum". Urol., 43: 453, 1994.

*59. CHANG, D.T.; KIRSCH, A.J.; SAWCZUK, I.S.: "Oliguria during laparoscopic surgery". J. Endourol., 8: 349, 1994.

**60. HAZEBROEK, E.; DE BRUIN, R.; BOUVY, N. y cols.: "Long-term impact of neumoperitoneum used for laparoscopic donor nephrectomy on renal function and histomorphology in donor and recipient rats". Ann. Surg., 237: 351, 2003.

61. GULER, C.; SADE, M.; KIRKALI, Z.: "Renal effect of carbon dioxide insufflation in rabbit pneumoperitoneum model". J. Endourol., 12: 367, 1998.

62. LINDSTRÖM, P.; WADSTRÖM, J.; OLLERSTAM, A. y cols.: "Effects of increased intra-abdominal pressure and volume expansion on renal function in the rat". Nephrol Dial Transplant, 18: 2269, 2003.

*63. STOWE, N.T.; SUNG, G.T.; SOBEL, J.J. y cols.: "Endothelin antagonist attenuation pneumoperitoneum-induced fall in GFR in a rat model". J. Endourol., 12: 97, 1998.

*64. KIM, F.; RATNER, L.; KAVOUSSI, L.: "Renal transplantation: Laparoscopic live donor nephrec- tomy”. Urol. Clin. of North Am., 27: 777, 2000.

*65. MERLIN, T.; SCOTT, D.; RAO, M. y cols.: "The safety and efficacy of laparoscopic live donor nephrectomy; a systematic review". Transplantation, 70: 1659, 2000.

66. JONES, K.; PETERS, T.; WALKER, G.: “Anteriorretroperitoneal living donor nephrectomy: Technique and outcomes". Am. Surgeon., 65: 197, 1999.

67. GILL, D.S.; CARBONE, J.M.; CALYMAN, R.V. y cols.: "Laparoscopic live donor nephrectomy". J. Endourol., 8: 143, 1994.

*68. JACOBS, S.C.; CHO, E.; FOSTER, C. y cols.: "Laparoscopic live donor nephrectomy: The University of Maryland 6-year experience". J. Urol.,171: 47, 2004.

*69. KHAULI, R.B.; HUSSEIN, M.; SHAAR, A. y cols.: "A prospective evaluation of laparoscopic donor nephrectomy versus open donor nephrectomy". Transplant Proc., 35: 2552, 2003.

*70. NOVICK, A.: "Laparoscopic live donor nephrectomy”. Urology, 53: 668, 1999.

**71. ABREU, S.C.; GOLDFARB, D.A.; DERWEESH, I. y cols.: "Factors related to delayed graft function after laparoscopic live donor nephrectomy". J. Urol., 171: 52, 2004.

*72. LONDON, E.; RUDICH, S.; McVICAR, J. y cols.: "Equivalent renal allograft function with laparoscopic versus open live donor nephrectomies". Transplant Proc., 31: 258, 1999.

*73. NOGUEIRA, J.; CANGRO, C.; FINK, J. y cols.: "A comparison of recipient renal outcomes with laparoscopic versus open live donor nephrectomy". Transplantation, 67: 722, 1999.

*74. SIMFOROOSH, N.; BASSIRI, A.; ZIAEE, S.A.M. y cols.: "Laparoscopic versus open live donor nephrectomy: The first randomized clinical trial". Transplant Proc., 35: 2553, 2003.

*75. KAVOUSSI, L.R.; RATNER L.E: "Laparoscopic donor nephrectomy”. Kidney Int., 57: 2175, 2000.

76. AKHTAR, K.; KAMALSKYASL, I.D.; LAMB, WR. y cols.: "Metabolic and inflammatory responses after laparoscopic and open inguinal hernia repair”. Ann. R. Coll. Surg. Engl., 80: 125, 1998.

*77. ELLSTROM, M.; BENGTSSON, A.; TYLAMAN, M. y cols.: "Evaluation of tissue trauma after laparoscopic and abdominal hysterectomy: Measurements of neutrophil activation and release of interleukin-6, Cortisol, and C-reactive protein". J. Am. Coll. Surg., 182: 423, 1996.

**78. FORNARA, P.; DOEHN, C.; SEYFARTH, M. y cols.: "Why is urological laparoscopy minimally invasive?". Eur. Urol., 37: 241, 2000.

**79. AMBROS, J.T.; HERRERO-FRESNEDA, I.; BORAU, O.G. y cols.: "Ischemic preconditioning in solid organ transplantation: From experimental to clinics". Transplant Int., 20: 219, 2007.

**80. OLTEAN, M.; MERA, S.; OLOFSSON, R. y cols.: "Transplantation of preconditioned intestinal grafts is associated with lower inflamatory activation and remote organ injury in rats". Transplant Proc., 38: 1775, 2006. 